\title{
Integrated dispersive structures for bandwidth-enhancement of silicon grating couplers
}

\author{
Rouven H. Klenk ${ }^{1}$. Christian Schweikert ${ }^{1}$ (D) Niklas Hoppe ${ }^{1}$ (D) - Lotte Nagy ${ }^{1}$. \\ Raik Elster $^{1} \cdot$ Wolfgang Vogel $^{1}$ D . Manfred Berroth ${ }^{1}$
}

Received: 17 September 2019 / Accepted: 4 January 2020 / Published online: 8 February 2020

(c) The Author(s) 2020

\begin{abstract}
In photonic integrated circuits grating couplers are commonly used to establish an efficient and stable fiber-to-chip link. However, the actual coupling efficiency of a fiber-to-chip interface depends strongly on the used wavelength and exhibits a maximum at a distinct target wavelength, determined by grating design parameters. In this paper, an enhancement of the optical bandwidth of silicon grating couplers by adding integrated dispersive structures is discussed. These are realized by single layers, prism-like geometries and additional silicon nitride gratings. Theoretical considerations for a bandwidth-enhancement by dispersive layers are performed and applied to an existing grating coupler design. A simulated 1dB-bandwidth of up to $90 \mathrm{~nm}$ at a maximum efficiency of $-0.65 \mathrm{~dB}$ in the $\mathrm{C}$-band could be achieved, which is an enhancement to a factor of about 2 compared with the original coupler design.
\end{abstract}

Keywords Grating coupler · Silicon-on-insulator $\cdot$ Bandwidth-enhancement

\section{Introduction}

For photonic integrated circuits used in communication systems, metrology and sensing applications up to quantum experiments, an efficient fiber-to-chip link is essential. For this task, grating couplers are commonly used due to their ease of integration and accessibility all over the chip surface. Recent coupler designs show excellent coupling efficiencies of up to $-0.5 \mathrm{~dB}$ (Hoppe et al. 2020), see Fig. 1.

This article is part of the Topical Collection on Numerical Simulation of Optoelectronic Devices.

Guest edited by Angela Thränhardt, Karin Hinzer, Weida Hu, Stefan Schulz, Slawomir Sujecki and Yuhrenn Wu.

Christian Schweikert

christian.schweikert@int.uni-stuttgart.de

Niklas Hoppe

niklas.hoppe@int.uni-stuttgart.de

1 Institute of Electrical and Optical Communications Engineering, University of Stuttgart, Pfaffenwaldring 47, 70569 Stuttgart, Germany 

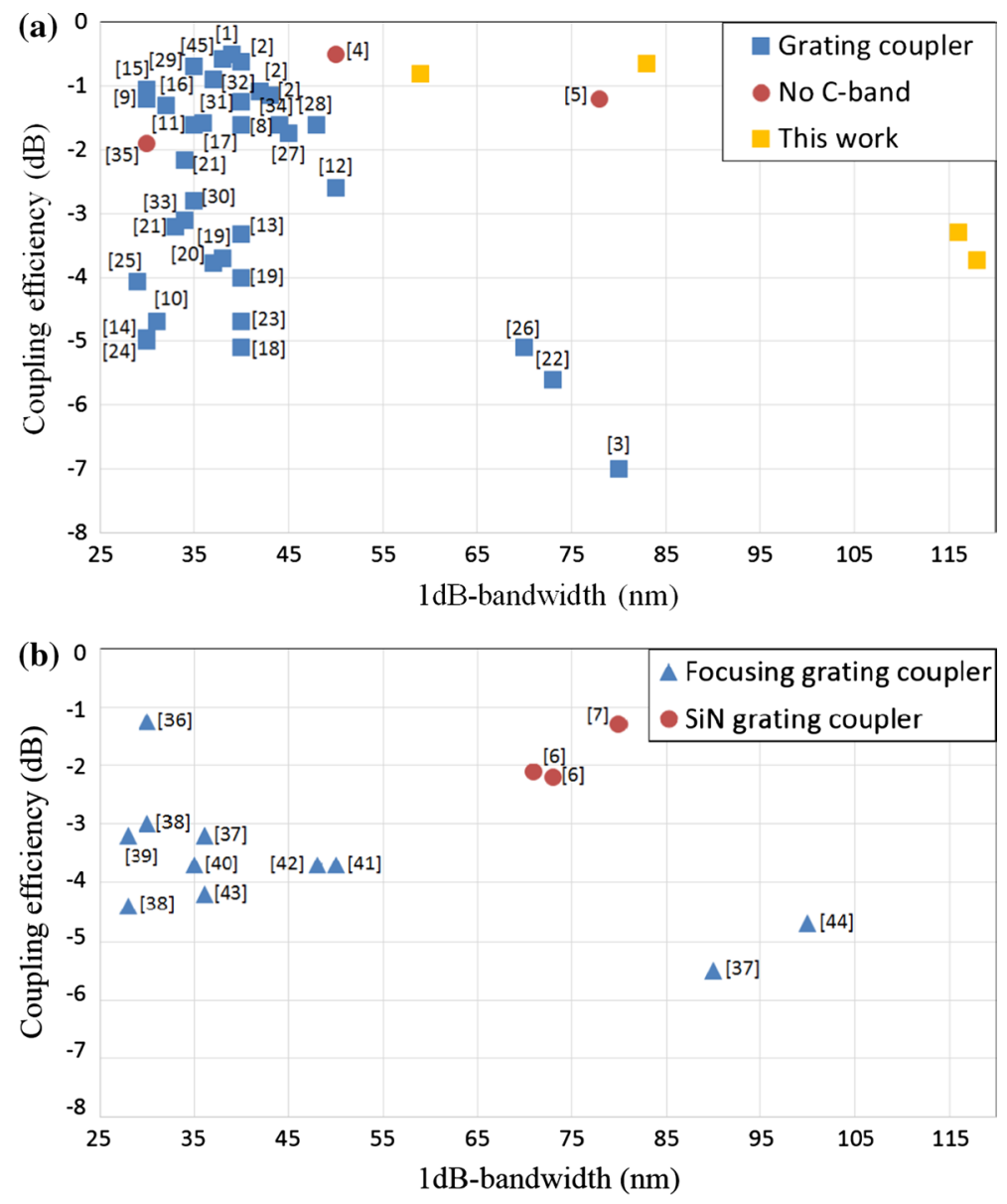

Fig. 1 A comparison of published grating couplers is shown. The considered attributes are the maximal coupling efficiency and the corresponding 1dB-bandwidth. In (a) only non-focusing grating couplers are shown and separated in C-band and no C-band. The focusing grating couplers in (b) are seperated in Si-based and SiN-based technologies. Excluding this works results, all couplers are measured. [1] Hoppe et al. (2020); [2] Zaoui et al. (2014); [3] Chen et al. (2011); [4] Notaros et al. (2016); [5] Wade et al. (2015); [6] Mak et al. (2018); [7] Sacher et al. (2014); [8] Van Laere et al. (2007); [9] Chen et al. (2010); [10] Chen et al. (2008b); [11] Vermeulen et al. (2009); [12] Roelkens et al. (2008); [13] Schrauwen et al. (2007); [14] Chen et al. (2008a); [15] Zhang et al. (2013); [16] Benedikovic et al. (2015a); [17] Selvaraja et al. (2009); [18] Taillaert et al. (2006); [19] Halir et al. (2010); [20] Liu et al. (2010); [21] Benedikovic et al. (2014); [22] Chen et al. (2012); [23] Scheerlinck et al. (2007); [24] Halir et al. (2012); [25] Subbaraman et al. (2012); [26] Xu et al. (2013); [27] Ding et al. (2013); [28] Zaoui et al. (2013); [29] Benedikovic et al. (2015b); [30] Wang et al. (2010); [31] Ding et al. (2014b); [32] Marchetti et al. (2017); [33] Lee et al. (2016); [34] Vermeulen et al. (2010); [35] Anastasia et al. (2012); [36] Mekis et al. (2011); [37] Wang et al. (2016); [38] Cheng et al. (2012); [39] Cheng and Tsang (2014); [40] Halir et al. (2014); [41] He et al. (2012); [42] Wang et al. (2014); [43] Wang et al. (2015); [44] Zhong et al. (2014); [45] Ding et al. (2014a)

Like the grating coupler in Zaoui et al. (2014), whose design is used in this work, the high coupling efficiency is achieved by a aperiodic structured silicon grating to match the Gaussian fiber mode properly, and by a backside mirror for a better coupling directionality. With a suitable packaging process (see Snyder and OBrien 2013; 
Hoppe et al. 2017) a compact and stable fiber-to-chip link can be realized. However, the spectral distribution of the efficiency of grating couplers is not uniform, but has a maximum at a distinct wavelength and then decays on both sides, resulting in a limited optical bandwidth of about $40 \mathrm{~nm}$ (Hoppe et al. 2020; Zaoui et al. 2014). There are other designs with enhanced bandwidth (Chen et al. 2011, 2012; Xu et al. 2013), but reduced efficiency. Obviously, there is a trade-off between maximal coupling efficiency and bandwidth.

A comprehensive collection of published grating couplers is shown in Fig. 1. The broadest bandwidth of $80 \mathrm{~nm}$ is reported in Chen et al. (2011) with a maximal coupling efficiency of $-7 \mathrm{~dB}$ for a grating coupler. As shown in Fig. 1a, the work presented in Notaros et al. (2016) provides a high coupling efficiency of $-0.5 \mathrm{~dB}$. The result in Wade et al. (2015) has a good balance between the coupling efficiency of $-1.2 \mathrm{~dB}$ and a $1 \mathrm{~dB}$-bandwidth of $78 \mathrm{~nm}$. However, both of them are not designed for C-band communications. The focusing grating couplers from Mak et al. (2018) and Sacher et al. (2014), depicted in Fig. 1b, show similar behavior as Wade et al. (2015), but they are also not devised for C-band applications. Furthermore, these couplers are fabricated in silicon nitride.

One approach to extend the usable wavelength range is to tune the gratings and shift the spectral distribution of the efficiency, e.g. by using heaters (Kim et al. 2015), but this method needs additional electrical control circuitry and consumes power. Another possibility is described in Molina-Fernández et al. (2017). There, a silicon-prism is used on top of the cladding above the grating coupler to vary the angle of incidence for different wavelengths. Following the simulation in Molina-Fernández et al. (2017), this method increases the $1 \mathrm{~dB}$-bandwidth to $126 \mathrm{~nm}$ in the C-band, but this method requires additional effort for fabrication and placement. In this work, we propose an integrated planar dispersive structure on top of the grating coupler. For that purpose simulations are used to determine the optical properties. The structure can be fabricated on wafer level using standard semiconductor processing technology. First, a short look at the simulation environment is given. Then the requirements for the dispersive structure are motivated and on this basis the discussion of the structured and unstructured cladding follows. At last, an integrated silicon nitride grating is shown, which enhances the bandwidth and can be realized in a common material system. In the conclusion and outlook the results are summarized.

\section{Design of an integrated dispersive structure}

\subsection{Simulation environment}

The optical simulations are based on the eigenmode expansion method (EME) of the full-vectorial Maxwell solver in the cavity modelling framework (CAMFR) (Bienstman 2001; Bienstman and Baets 2001) and performed with transverse electric waveguide modes. 120 eigenmodes are used to simulate the grating coupler without and with a dispersive structure. For the more extensive optimization of geometrical parameters the number of eigenmodes is reduced to 80 for speeding up the calculations. Refractive indices are based on numerical data from the results in Li (1980) and Agrawal (1995). 
While the electrical field of the grating coupler is simulated numerically, the electrical field of the SMF-28 fiber mode is approximated analytically with a Gaussian beam.

\subsection{Requirements for the dispersive structure}

The following analysis is based on the grating coupler geometry described in Zaoui et al. (2014). Its coupling efficiency is simulated at different wavelengths for different coupling angles $\theta$ and positions $z$ along the grating coupler. The results are shown in Fig. 2a-c.

As depicted in Fig. 2d, the coupling angle for the maximum coupling efficiency varies from about $13^{\circ}$ to about $5^{\circ}$ for wavelengths ranging from 1.50 to $1.60 \mu \mathrm{m}$ respectively. The position $z$ is nearly the same. Thus, for getting the maximum coupling efficiency for a given wavelength, it is required to change the coupling angle $\theta$, whereas the position $z$ is left unchanged. When the fiber is kept at a fixed position and angle, the same effect is achieved by introducing a dispersive medium with an angular dispersion $\Delta \theta / \Delta \lambda$ of $-1.4 \mu \mathrm{m}^{-1}$, depicted as Black Box in Fig. 3.

Assuming that the Black Box is lossless and the $z$-dependence is neglected, the normalized efficiency of this setup will be close to 1 within a $100 \mathrm{~nm}$ bandwidth. It has to be mentioned, that the angular dispersion and the dispersion of the refractive index $\Delta n / \Delta \lambda$ are not the same, but they have the same unit of $\mu \mathrm{m}^{-1}$, and they are proportional to each other,
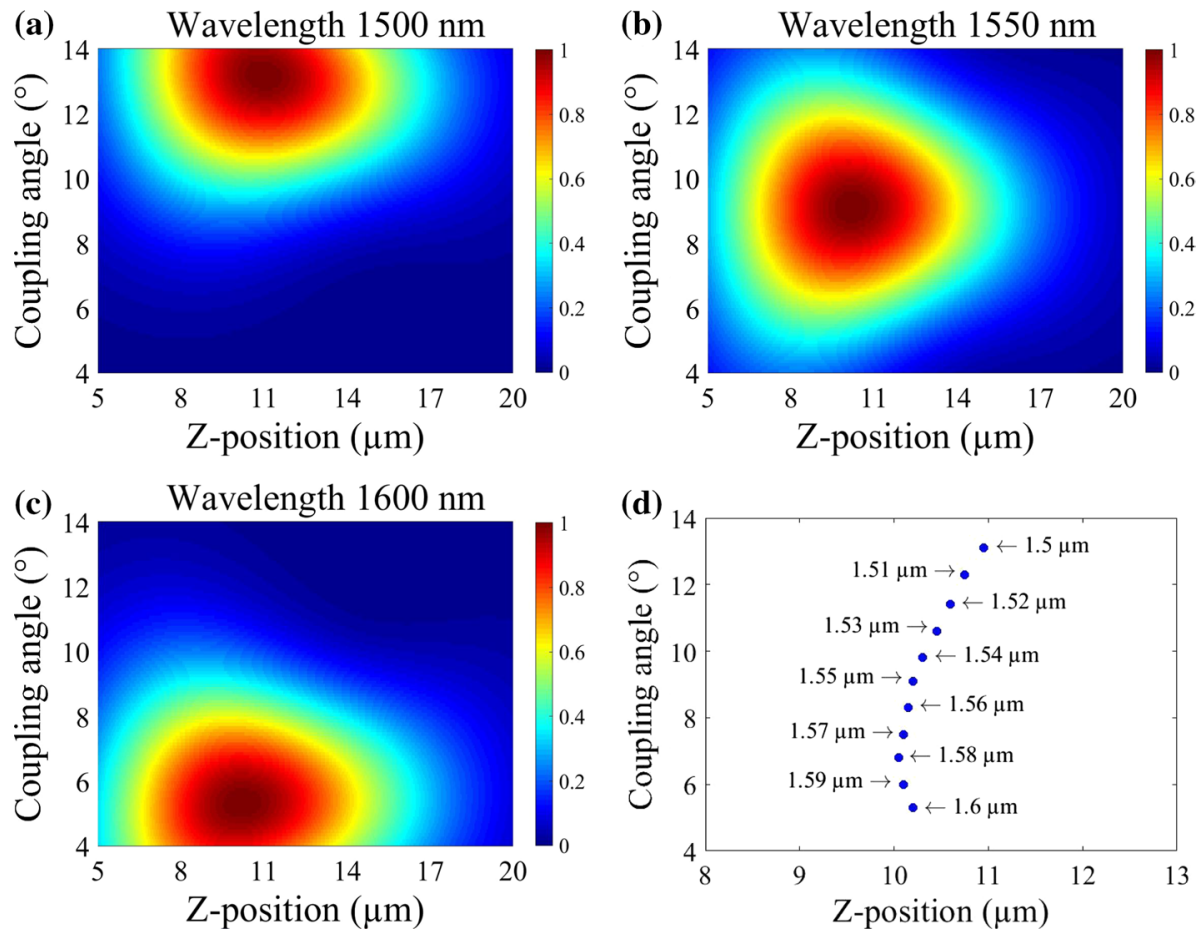

Fig. 2 The results of the simulated normalized coupling efficiency for $1500 \mathrm{~nm}$ (a), $1550 \mathrm{~nm}$ (b) and $1600 \mathrm{~nm}$ (c) by varying coupling angle and fiber position along the grating coupler is shown in color code. The positions of the incoming light for maximal coupling efficiency of different wavelengths are marked in (d) 
Fig. 3 Schematic of the grating coupler with the incoming light and the Black Box. The change $\Delta \theta$ depends on the wavelength of the light and is induced by the Black Box

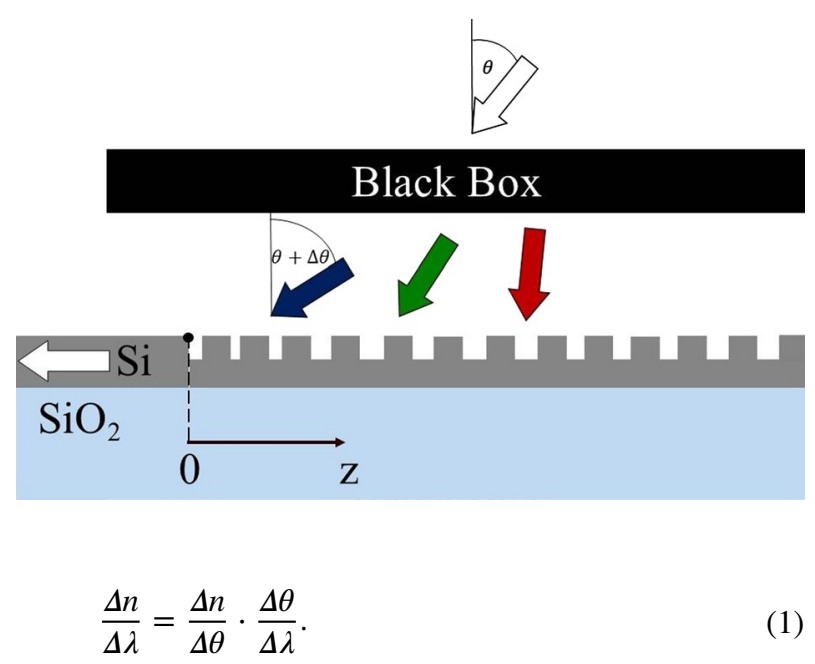

The factor $\Delta n / \Delta \theta$ depends on the geometry and the materials of the Black Box. In the following dispersion is related to the dispersion of refractive index, which is considered in the next chapter.

\subsection{Dispersive cladding}

The first approach to realize the Black Box is using a simple layer of a dispersive material. Therefore, region I and II in Fig. 4 are set to behave like silicon dioxide. Only the cladding of the grating coupler, named region III, is considered dispersive. We evaluate the behavior of a dispersive region on the basis of a virtual material with a refractive index of 1.444 at $1550 \mathrm{~nm}$. This ensures that the standard configuration and the structure with the Black Box are identical at $1550 \mathrm{~nm}$ for better comparison. The dispersion of this virtual material is assumed to be constant over wavelength. The fiber is placed according to the optimum of Fig. 2b.

Solving the transition into region III by using Snells law, $\Delta n / \Delta \theta$ is negative. As described, the angular dispersion $\Delta \theta / \Delta \lambda$ for maximal coupling efficiency is also negative

Fig. 4 The schematic view of the simulated fiber-to-chip link is shown. Regions I-III are considered as dispersive in different combinations. The indicated grating coupler on the bottom is simulated with a backside reflector as presented in Zaoui et al. (2014)

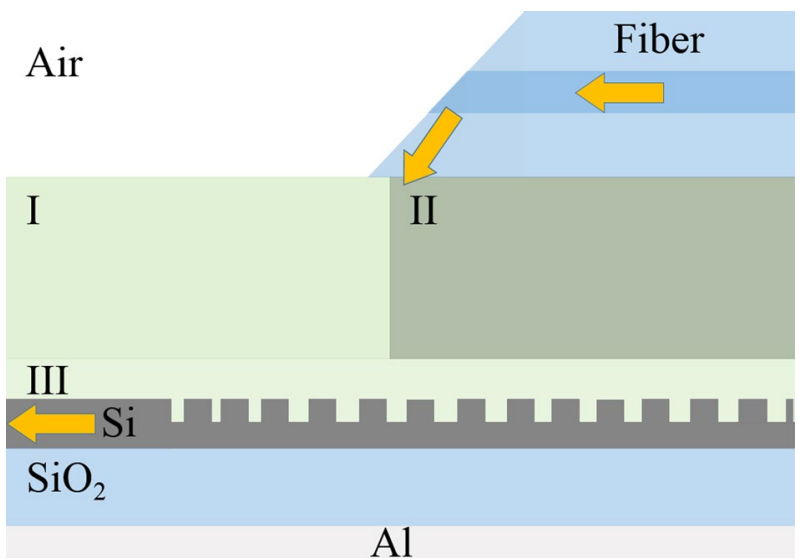


Fig. 5 Simulated $1 \mathrm{~dB}-$ and $3 \mathrm{~dB}-$ bandwidths of the same grating coupler with different dispersions of region III (a) and region I (b)
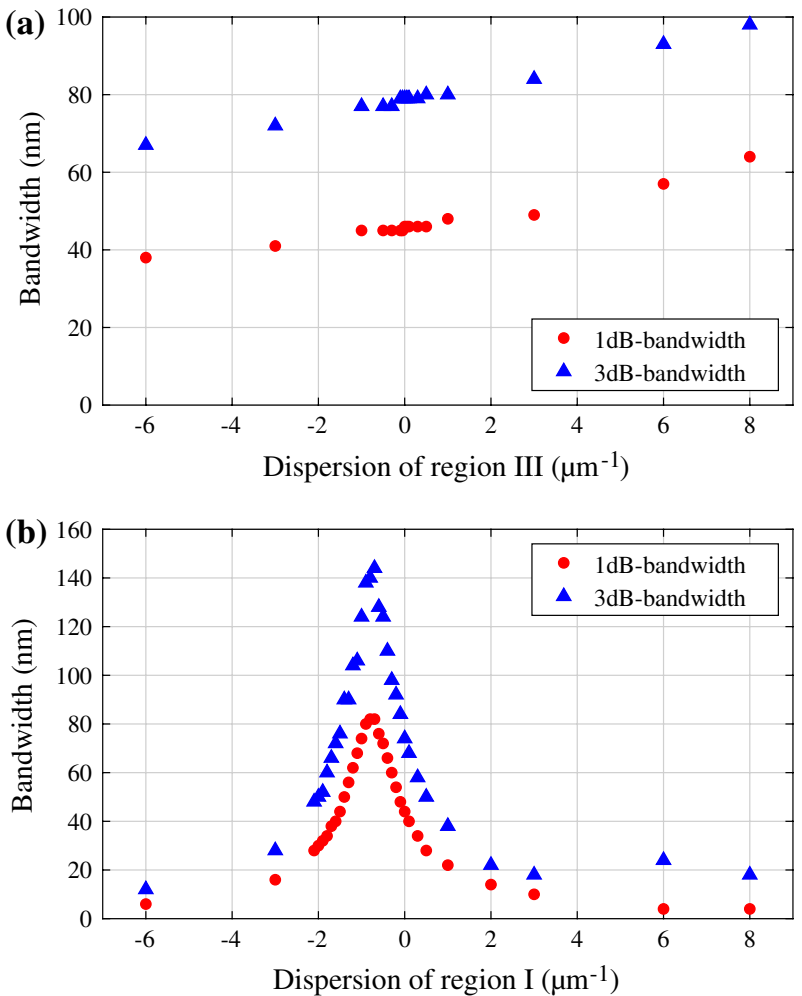

$\left(-1.4 \mu \mathrm{m}^{-1}\right)$. Thus, according to Eq. (1), an enhancement of the bandwidth is expected at positive dispersions $\Delta n / \Delta \lambda$. For a region III with a thickness of $1 \mu \mathrm{m}$, the simulations show a dispersion-dependent increase of the bandwidth, as depicted in Fig. 5a. The $1 \mathrm{~dB}$-bandwidth as well as the $3 \mathrm{~dB}$-bandwidth rise with a slope of $1.8 \mathrm{~nm} / \mu^{-1}$ and $2.2 \mathrm{~nm} / \mu \mathrm{m}^{-1}$, respectively. This result validates the method to enhance the optical bandwidth of a grating coupler by just adding a dispersive layer. To have a significant effect on optical bandwidth, the material dispersion should be high. While silicon dioxide provides only a very low dispersion, doped glasses (Polyanskiy 2018; Fleming 1978) or adhesives, as used for the packaging process, are more promising candidates.

\subsection{Structured dispersive cladding}

As seen in the previous section, the dispersion of the Black Box should be high to have significant influence on the optical bandwidth of the coupler and a suitable material has to be found for the uniform film. A more prism-like effect is created by adding a layer with a vertical boundary between region I and II, as shown in Fig. 4. Now, region III is the standard passivation oxide layer with a thickness of $0.5 \mu \mathrm{m}$. Region I is dispersive, while region II has also the properties of silicon dioxide. Through iterative simulations, the thickness of region I and region II is optimized to $12.4 \mu \mathrm{m}$. The boundary surface is located at $z=6.14 \mu \mathrm{m}$. 
Fig. 6 Coupling efficiency of the considered grating coupler in dependence of the wavelength without and with an optimized dispersive structure

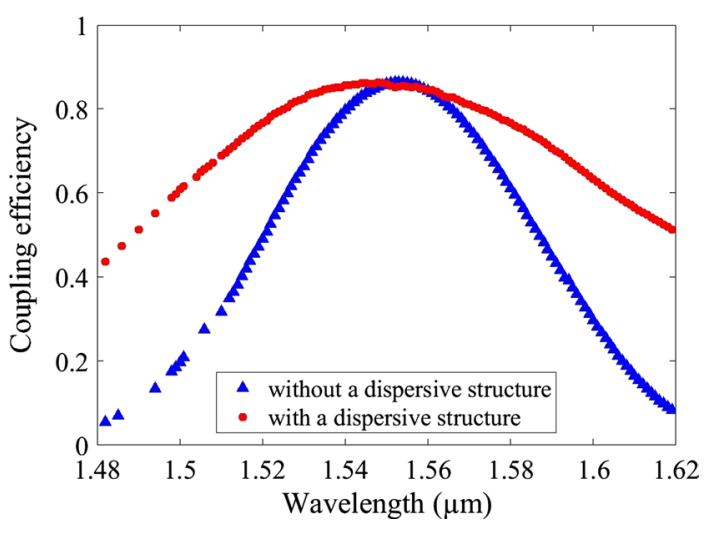

As illustrated in Fig. 5b, there is again an effect on the optical bandwidth, now with a distinct peak at $-0.77 \mu \mathrm{m}^{-1}$ showing a $1 \mathrm{~dB}$-bandwidth of $83 \mathrm{~nm}$. The factor of this enhancement is about 1.97 compared to the original unmodified coupler, see Fig. 6.

This principle can easily be applied to other grating coupler designs. Simulated values of additional grating designs at INT (Hoppe et al. 2019) with this dispersive structure are shown in Fig. 1a. Their 1dB-bandwidths are enhanced from 95 to $116 \mathrm{~nm}$ and from 109 to $118 \mathrm{~nm}$, respectively.

\subsection{Integrated silicon nitride grating}

The next step of evolution is to realize the Black Box by another grating on top of the silicon grating. The top grating is the dispersive element, which feeds the coupling grating. Here, the dispersion is not provided by a significant dispersion of the refractive index of one material, but by the effective dispersion of the whole structure. There are silicon grating couplers with an additional grating on top of the actual grating coupler (Xiao et al. 2012) and approaches, which combine silicon and silicon nitride (Wade et al. 2015; Mak et al. 2018; Sacher et al. 2014; Masanovic et al. 2005). But this work focuses on the combination of a Si-based coupler in the C-band with a high efficiency and broad bandwidth. The position, thickness, fill factor and periodicity of the additional grating have to be aligned. A schematic is shown in Fig. 7.

In order to compare different grating geometries a figure of merit is defined

Fig. 7 The schematic view of a silicon grating coupler with a periodic silicon nitride grating above

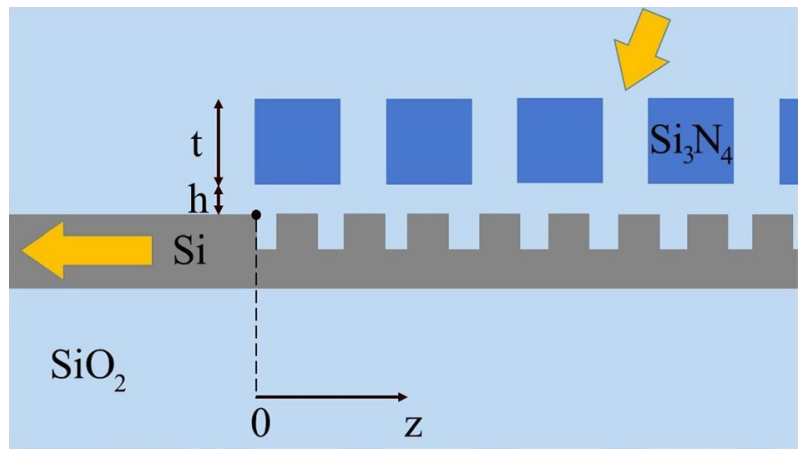




$$
F O M=\Delta \lambda_{1 d B} \cdot \eta_{1550},
$$

where $\eta_{1550}$ is the efficiency at a wavelength of $1550 \mathrm{~nm}$. For the calculation of the FOM, the efficiencies (Fig. 8) of ten wavelengths, including $1550 \mathrm{~nm}$, are calculated and the $1 \mathrm{~dB}$-bandwidth is approximated by a cubic interpolation.

First a simple Monte Carlo simulation was implemented, i.e. a variety of different parameter combinations is simulated. The configuration with the best FOM is the starting point for a subsequent investigation with more limited ranges of parameter values and higher resolution.

Figure 9 shows part of a sweep of thickness $t$, height $h$ and horizontally shift along the z-axis (as defined in Fig. 7) of an additional periodic silicon nitride grating above the silicon grating coupler. The fill factor of the shown sweeps is set to 0.5 , while one period has a length of $800 \mathrm{~nm}$.

After the evaluation of each configuration, the algorithm leads to a structure, which has a $1 \mathrm{~dB}$-bandwidth of $58 \mathrm{~nm}$ with a maximal coupling efficiency of about $-0.56 \mathrm{~dB}$.

Due to the large number of the required configurations for high accuracy, the complete pass through the implemented program, like for the additional periodic grating before, takes a long time. Therefore, another more efficient approach was used to find an adequate additional aperiodic grating. In a first step, only the thickness and the distance to the coupler of a silicon nitride layer all over the coupler are varied. After the optimization of these parameters, the fill factor, horizontal shift and periodicity are improved. In a last step the algorithm searches for an enhancement with an aperiodic design. The resulting aperiodic nitride grating with a $190 \mathrm{~nm}$ thick layer leads to a $1 \mathrm{~dB}$-bandwidth of $63 \mathrm{~nm}$ with a maximal coupling efficiency of $-0.71 \mathrm{~dB}$.

A comparison of the coupler without additional grating, with a periodic and an aperiodic grating are presented in Fig. 10. As shown, both modifications enhance the $1 \mathrm{~dB}$-bandwidth, but under degeneration of the maximal coupling efficiency. However, this decrease is relatively small considering Fig. 1.

Fig. 8 Simulated efficiency of an arbitrary silicon nitride grating geometry over a silicon grating coupler for different wavelengths and its cubic interpolation line

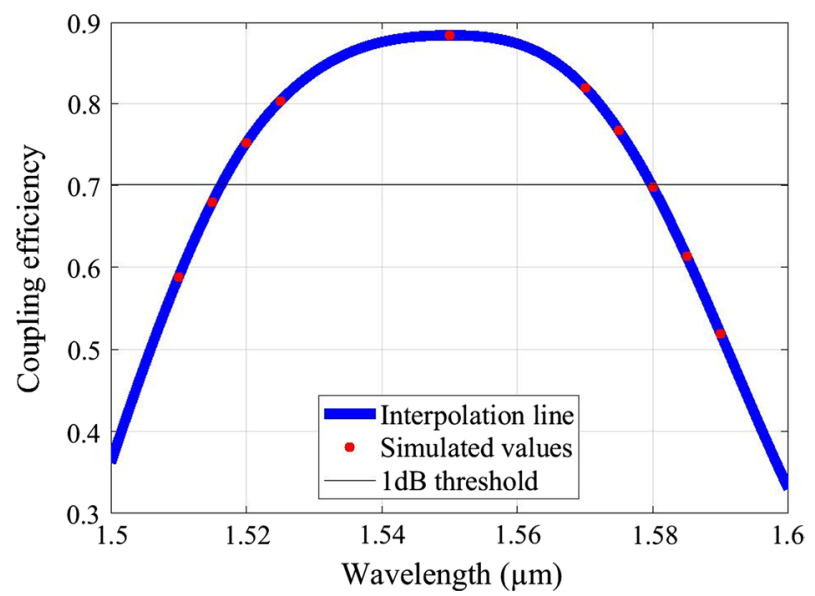


Fig. 9 Influence of a geometrical sweep in thickness, height and horizontal shift of the additional $\mathrm{SiN}$ grating. While variing the parameter of interest, the other parameters kept constant. In (a) the height is set to $202 \mathrm{~nm}$ and the shift to $-350 \mathrm{~nm}$, in (b) the thickess corresponds to $224 \mathrm{~nm}$ and the shift to $-350 \mathrm{~nm}$ and in (c) the thickness equals to $224 \mathrm{~nm}$ and the height to $202 \mathrm{~nm}$
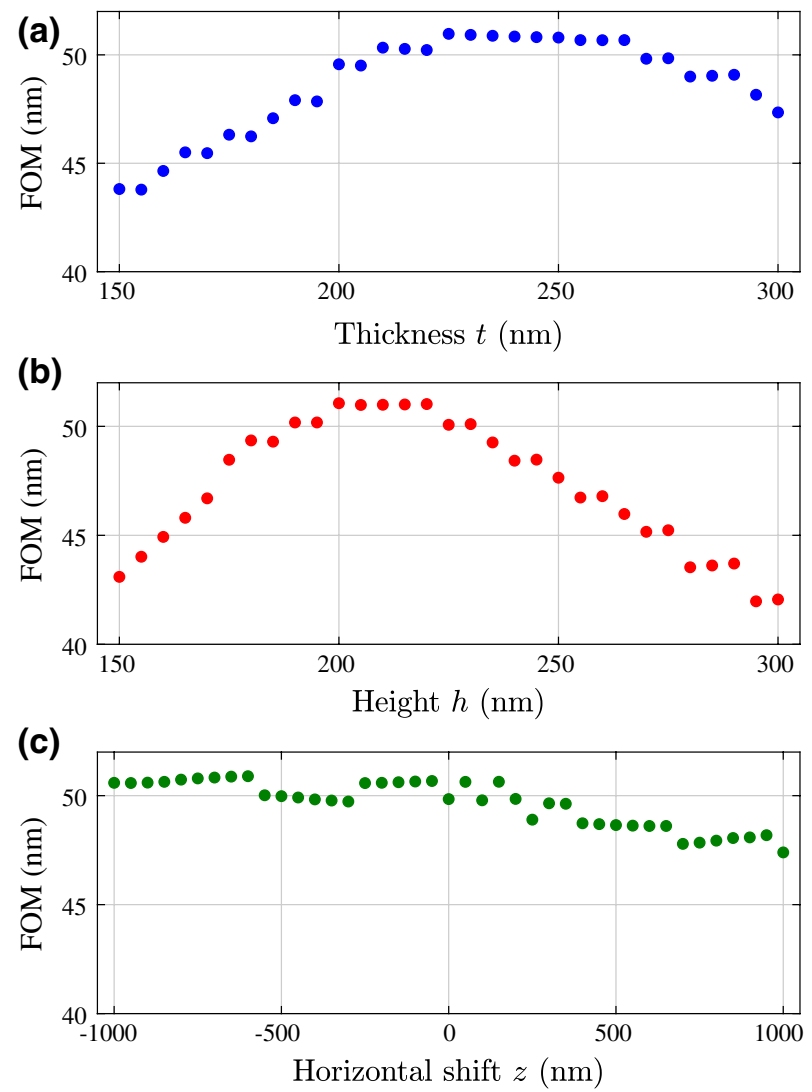

Fig. 10 The coupling efficiency over the wavelength is shown for the grating coupler without an additional grating, with a periodic and an aperiodic silicon nitride grating

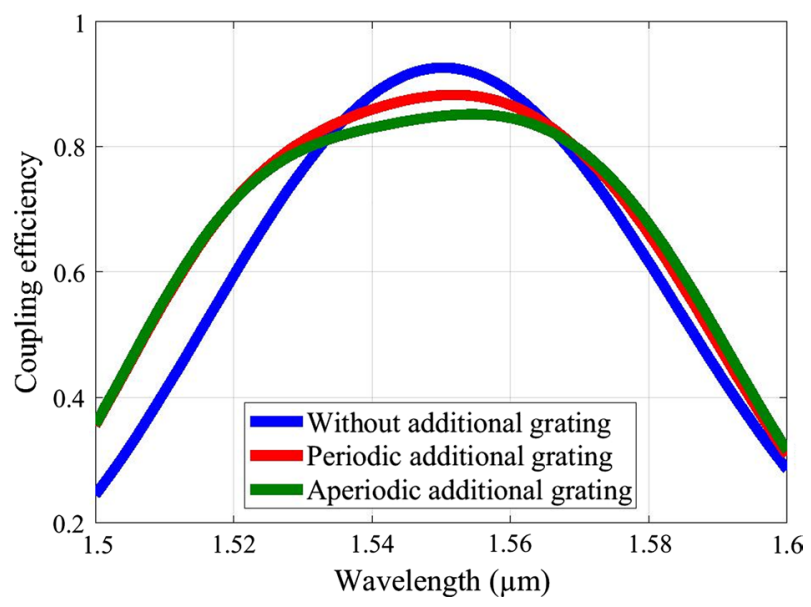




\section{Conclusion and outlook}

The requirements for an integrated bandwidth-enhancing dispersive structure on top of a state-of-the-art grating coupler, and various designs and their respective simulations are presented. The bandwidth-enhancement of a dispersive cladding is approximately $1.8 \mathrm{~nm} / \mu \mathrm{m}^{-1}$ and $2.2 \mathrm{~nm} / \mu \mathrm{m}^{-1}$ for the $1 \mathrm{~dB}$-bandwidth and $3 \mathrm{~dB}$-bandwidth, respectively. Using an additional structure with a dispersion of $-0.77 \mu \mathrm{m}^{-1}$ for one region enhances the 1dB-bandwidth by a factor of 1.97 . For all these approaches the maximal coupling efficiency remains nearly constant. Using an additional aperiodic silicon nitride grating on top of the grating coupler a $1 \mathrm{~dB}$-bandwidth of $63 \mathrm{~nm}$ is achieved, but the maximal coupling efficiency is reduced to $-0.71 \mathrm{~dB}$.

The work results are based on silicon grating designs in a $250 \mathrm{~nm}$ SOI platform. Furthermore, these dispersive structures are adaptable to other designs. Thanks to their simple design, the structures presented in this article are interesting candidates for production and down-market products.

Acknowledgements Open Access funding provided by Projekt DEAL. The authors would like to thank Dr. W. S. Zaoui and A. Kunze for the adapted aperiodic grating design with backside mirror. Further, we thank C. Raichle for supporting the simulations regarding the enhancement of the bandwidth.

Funding Funding was provided by Bundesministerium für Wirtschaft und Energie (DE) (Grant No. ZF4641301DF8).

Open Access This article is licensed under a Creative Commons Attribution 4.0 International License, which permits use, sharing, adaptation, distribution and reproduction in any medium or format, as long as you give appropriate credit to the original author(s) and the source, provide a link to the Creative Commons licence, and indicate if changes were made. The images or other third party material in this article are included in the article's Creative Commons licence, unless indicated otherwise in a credit line to the material. If material is not included in the article's Creative Commons licence and your intended use is not permitted by statutory regulation or exceeds the permitted use, you will need to obtain permission directly from the copyright holder. To view a copy of this licence, visit http://creativecommons.org/licenses/by/4.0/.

\section{References}

Agrawal, G.: Nonlinear Fiber Optics. University of Rochester, Rochester (1995)

Anastasia, N., Xiao, X., Yang, B., Chu, T., Yu, J.Z., Yu, Y.D.: Design and characterization of a top cladding for silicon-on-insulator grating coupler. Chin. Phys. Lett. 29, 114213 (2012)

Benedikovic, D., Cheben, P., Schmid, J.H., Xu, D.X., Lapointe, J., Wang, S., Halir, R., Ortega-Moñux, A., Janz, S., Dado, M.: High-efficiency single etch step apodized surface grating coupler using subwavelength structure. Laser Photonics Rev. 8, L93-L97 (2014)

Benedikovic, D., Alonso-Ramos, C., Cheben, P., Schmid, J.H., Wang, S., Xu, D.X., Lapointe, J., Janz, S., Halir, R., Wangüemert-Pérez, J.G., Molina-Fernández, I., Fédéli, J.M., Vivien, L., Dado, M.: High-directionality fiber-chip grating coupler with interleaved trenches and subwavelength indexmatching structure. Opt. Lett. 40, 4190-4193 (2015a)

Benedikovic, D., Cheben, P., Schmid, J.H., Xu, D.X., Lamontagne, B., Wang, S., Lapointe, J., Halir, R., Ortega-Moñux, A., Janz, S., Dado, M.: Subwavelength index engineered surface grating coupler with sub-decibel efficiency for 220-nm silicon-on-insulator waveguides. Opt. Express 23, 2262822635 (2015b)

Bienstman, P.: Rigorous and efficient modelling of wavelength scale photonic components, Ghent University (2001)

Bienstman, P., Baets, R.: Optical modelling of photonic crystals and vcsels using eigenmode expansion and perfectly matched layers. Opt. Quantum Electron. 33, 327-341 (2001) 
Chen, X., Li, C., Tsang, H.K.: Characterization of silicon-on-insulator waveguide chirped grating for coupling to a vertical optical fiber. In: 2008 IEEE/LEOS International Conference on Optical MEMs and Nanophotonics, pp. 56-57 (2008a)

Chen, X., Li, C., Tsang, H.K.: Fabrication-tolerant waveguide chirped grating coupler for coupling to a perfectly vertical optical fiber. IEEE Photonics Technol. Lett. 20, 1914-1916 (2008b)

Chen, X., Li, C., Fung, C.K.Y., Lo, S.M.G., Tsang, H.K.: Apodized waveguide grating couplers for efficient coupling to optical fibers. IEEE Photonics Technol. Lett. 22, 1156-1158 (2010)

Chen, X., Fung, C.K.Y., Chen, Y.M., Tsang, H.K.: Subwavelength waveguide grating coupler for fiberto-chip coupling on soi with $80 \mathrm{~nm} 1 \mathrm{~dB}$-bandwidth. In: CLEO: 2011-Laser Science to Photonic Applications, pp. 1-2 (2011)

Chen, X., Xu, K., Cheng, Z., Fung, C.K.Y., Tsang, H.K.: Wideband subwavelength gratings for coupling between silicon-on-insulator waveguides and optical fibers. Opt. Lett. 37, 3483-3485 (2012)

Cheng, Z., Tsang, H.K.: Experimental demonstration of polarization-insensitive air-cladding grating couplers for silicon-on-insulator waveguides. Opt. Lett. 39, 2206-2209 (2014)

Cheng, Z., Chen, X., Wong, C.Y., Xu, K., Tsang, H.K.: Apodized focusing subwavelength grating couplers for suspended membrane waveguides. Appl. Phys. Lett. 101, 101104 (2012)

Ding, Y., Ou, H., Peucheret, C.: Ultrahigh-efficiency apodized grating coupler using fully etched photonic crystals. Opt. Lett. 38, 2732-2734 (2013)

Ding, Y., Peucheret, C., Ou, H., Yvind, K.: Fully etched apodized grating coupler on the SOI platform with $-0.58 \mathrm{~dB}$ coupling efficiency. Opt. Lett. 39, 5348-5350 (2014a)

Ding, Y., Peucheret, C., Ou, H.: Ultra-low coupling loss fully-etched apodized grating coupler with bonded metal mirror. In: 11th International Conference on Group IV Photonics (GFP), pp. 139-140 (2014b)

Fleming, J.W.: Material Dispersion in Lightguide Glasses. Bell Laboratories, Murray Hill (1978)

Halir, R., Cheben, P., Schmid, J.H., Ma, R., Bedard, D., Janz, S., Xu, D.X., Densmore, A., Lapointe, J., Molina-Fernández, I.: Continuously apodized fiber-to-chip surface grating coupler with refractive index engineered subwavelength structure. Opt. Lett. 35, 3243-3245 (2010)

Halir, R., Zavargo-Peche, L., Xu, D.X., Cheben, P., Ma, R., Schmid, J.H., Janz, S., Densmore, A., Ortega-Moñux, A., Molina-Fernández, I., Fournier, M., Fédéli, J.M.: Single etch grating couplers for mass fabrication with DUV lithography. Opt. Quantum Electron. 44, 521-526 (2012)

Halir, R., Ortega-Moñux, A., Schmid, J.H., Alonso-Ramos, C., Lapointe, J., Xu, D., Wangüemert-Pérez, J.G., Molina-Fernández, I., Janz, S.: Recent advances in silicon waveguide devices using subwavelength gratings. IEEE J. Sel. Top. Quantum Electron. 20, 279-291 (2014)

He, L., He, Y., Pomerene, A., Hill, C., Ocheltree, S., Baehr-Jones, T., Hochberg, M.: Ultrathin siliconon-insulator grating couplers. IEEE Photonics Technol. Lett. 24, 2247-2249 (2012)

Hoppe, N., Haug, M., Vogel, W., Félix Rosa, M., Föhn, T., Rathgeber, L., Berroth, M.: Packaging process for efficient coupling using a grating coupler with backside mirror. In: 2017 International Conference on Numerical Simulation of Optoelectronic Devices (NUSOD), pp. 151-152 (2017)

Hoppe, N., Klenk, R.H., Rathgeber, L., Vogel, W., Berroth, M.: Bandwidth-enhancement of silicon grating couplers using dispersive coatings. In: 2019 International Conference on Numerical Simulation of Optoelectronic Devices (NUSOD), pp. 21-22 (2019)

Hoppe, N., Zaoui, W.S., Rathgeber, L., Wang, Y., Klenk, R.H., Vogel, W., Kaschel, M., Portalupi, S.L., Burghartz, J., Berroth, M.: Ultra-efficient silicon-on-insulator grating couplers with backside metal mirrors. IEEE J. Sel. Top. Quantum Electron. 26, 1-6 (2020)

Kim, J., Park, J., Han, S., Bae, M., Yoo, D., Lee, D., Park, H.: Tunable grating couplers for broadband operation using thermo-optic effect in silicon. IEEE Photonics Technol. Lett. 27, 2304-2307 (2015)

Lee, M.H., Jo, J.Y., Kim, D.W., Kim, Y., Kim, K.H.: Comparative study of uniform and nonuniform grating couplers for optimized fiber coupling to silicon waveguides. J. Opt. Soc. Korea 20, 291-299 (2016)

Li, H.H.: Refractive index of silicon and germanium and its wavelength and temperature derivatives. J. Phys. Chem. Ref. Data 9, 561-658 (1980)

Liu, L., Pu, M., Yvind, K., Hvam, J.M.: High efficiency, large-bandwidth silicon-on-insulator grating coupler based on a fully-etched photonic crystal structure. Appl. Phys. Lett. 96, 051126 (2010)

Mak, J.C.C., Wilmart, Q., Olivier, S., Menezo, S., Poon, J.K.S.: Silicon nitride-on-silicon bi-layer grating couplers designed by a global optimization method. Opt. Express 26, 13656-13665 (2018)

Marchetti, R., Lacava, C., Khokhar, A., Chen, X., Cristiani, I., Richardson, D.J., Reed, G.T., Petropoulos, P., Minzioni, P.: High-efficiency grating-couplers: demonstration of a new design strategy. Sci. Rep. 7, 16670 (2017) 
Masanovic, G.Z., Reed, G.T., Headley, W., Timotijevic, B., Passaro, V.M.N., Atta, R., Ensell, G., Evans, A.G.R.: A high efficiency input/output coupler for small silicon photonic devices. Opt. Express 13, 7374-7379 (2005)

Mekis, A., Gloeckner, S., Masini, G., Narasimha, A., Pinguet, T., Sahni, S., De Dobbelaere, P.: A grating-coupler-enabled cmos photonics platform. IEEE J. Sel. Top. Quantum Electron. 17, 597608 (2011)

Molina-Fernández, I., Halir, R., Ortega-Moñux, A., Wangüemert-Pérez, J.G., Chen, Y., He, J., Cheben, P., Schmid, J.H., Bucio, T.D., Khokhar, A.Z., Banakar, M., Grabska, K., Gardes, F.Y.: Broadband and high-performance devices for the silicon and silicon-nitride platforms. In: 2017 19th International Conference on Transparent Optical Networks (ICTON), pp. 1-4 (2017)

Notaros, J., Pavanello, F., Wade, M.T., Gentry, C.M., Atabaki, A., Alloatti, L., Ram, R.J., Popovíc, M.A.: Ultra-efficient cmos fiber-to-chip grating couplers. In: Optical Fiber Communication Conference, Optical Society of America, M2I.5 (2016)

Polyanskiy, M.: Refractive index database. https://refractiveindex.info. Accessed June 2018

Roelkens, G., Vermeulen, D., Van Thourhout, D., Baets, R., Brision, S., Lyan, P., Gautier, P., Fédéli, J.M.: High efficiency diffractive grating couplers for interfacing a single mode optical fiber with a nanophotonic siliconon-insulator waveguide circuit. Appl. Phys. Lett. 92, 131101 (2008)

Sacher, W.D., Huang, Y., Ding, L., Taylor, B.J.F., Jayatilleka, H., Lo, G.Q., Poon, J.K.S.: Wide bandwidth and high coupling efficiency $\mathrm{Si}_{3} \mathrm{~N}_{4}$-on-SOI dual-level grating coupler. Opt. Express 22, 10938-10947 (2014)

Scheerlinck, S., Schrauwen, J., Taillaert, D., Van Thourhout, D., Baets, R.: Efficient, broadband and compact metal grating couplers for silicon-on-insulator waveguides. In: 2007 Conference on Lasers and Electro-Optics (CLEO), pp. 1-2 (2007)

Schrauwen, J., Van Laere, F., Van Thourhout, D., Baets, R.: Focused-ion-beam fabrication of slanted grating couplers in silicon-on-insulator waveguides. IEEE Photonics Technol. Lett. 19, 816-818 (2007)

Selvaraja, S.K., Vermeulen, D., Schaekers, M., Sleeckx, E., Bogaerts, W., Roelkens, G., Dumon, P., Thourhout, D.V., Baets, R.: Highly efficient grating coupler between optical fiber and silicon photonic circuit. In: Conference on Lasers and Electro-Optics/International Quantum Electronics Conference, Optical Society of America, CTuC6 (2009)

Snyder, B., OBrien, P.: Packaging process for gratingcoupled silicon photonic waveguides using anglepolished fibers. IEEE Trans. Compon. Packag. Manuf. Technol. 3, 954-959 (2013)

Subbaraman, H., Xu, X., Covey, J., Chen, R.T.: Efficient light coupling into in-plane semiconductor nanomembrane photonic devices utilizing a sub-wavelength grating coupler. Opt. Express 20, 20659-20665 (2012)

Taillaert, D., Van Laere, F., Ayre, M., Bogaerts, W., Van Thourhout, D., Bienstman, P., Baets, R.: Grating couplers for coupling between optical fibers and nanophotonic waveguides. Jpn. J. Appl. Phys. 45, 6071-6077 (2006)

Van Laere, F., Roelkens, G., Ayre, M., Schrauwen, J., Taillaert, D., Van Thourhout, D., Krauss, T.F., Baets, R.: Compact and highly efficient grating couplers between optical fiber and nanophotonic waveguides. J. Lightwave Technol. 25, 151-156 (2007)

Vermeulen, D., Selvaraja, S., Verheyen, P., Lepage, G., Bogaerts, W., Roelkens, G.: High-efficiency silicon-on-insulator fiber-to-chip grating couplers using a silicon overlay. In: 6th International Conference on Group IV Photonics (GFP) (2009)

Vermeulen, D., Selvaraja, S., Verheyen, P., Lepage, G., Bogaerts, W., Absil, P., Thourhout, D.V., Roelkens, G.: High-efficiency fiber-to-chip grating couplers realized using an advanced cmoscompatible silicon-on-insulator platform. Opt. Express 18, 18278-18283 (2010)

Wade, M.T., Pavanello, F., Kumar, R., Gentry, C.M., Atabaki, A., Ram, R., Stojanović, V., Popović, M.A.: $75 \%$ grating couplers in a $45 \mathrm{~nm}$ microelectronics cmos process. In: 2015 IEEE Optical Interconnects Conference (OI), pp. 46-47 (2015)

Wang, Z., Tang, Y., Wosinski, L., He, S.: Experimental demonstration of a high efficiency polarization splitter based on a one-dimensional grating with a bragg reflector underneath. IEEE Photonics Technol. Lett. 22, 1568-1570 (2010)

Wang, Y., Wang, X., Flueckiger, J., Yun, H., Shi, W., Bojko, R., Jaeger, N.A.F., Chrostowski, L.: Focusing subwavelength grating couplers with low back reflections for rapid prototyping of silicon photonic circuits. Opt. Express 22, 20652-20662 (2014)

Wang, Y., Yun, H., Lu, Z., Bojko, R., Zhang, F., Caverley, M., Jaeger, N.A.F., Chrostowski, L.: Apodized focusing fully etched sub-wavelength grating couplers with ultralow reflections. In: 2015 Conference on Lasers and Electro-Optics (CLEO), pp. 1-2 (2015) 
Wang, Y., Yun, H., Lu, Z., Jaeger, N.A.F., Chrostowski, L.: State-of-the-art sub-wavelength grating couplers for silicon-on-insulator platform. In: 2016 IEEE Canadian Conference on Electrical and Computer Engineering (CCE CE), pp. 1-4 (2016)

Xiao, Z., Luan, F., Liow, T.Y., Zhang, J., Shum, P.: Design for broadband high-efficiency grating couplers. Opt. Lett. 37, 530-532 (2012)

Xu, X., Subbaraman, H., Covey, J., Kwong, D., Hosseini, A., Chen, R.T.: Colorless grating couplers realized by interleaving dispersion engineered subwavelength structures. Opt. Lett. 38, 3588-3591 (2013)

Zaoui, W.S., Kunze, A., Vogel, W., Berroth, M.: Cmoscompatible polarization splitting grating couplers with a backside metal mirror. IEEE Photonics Technol. Lett. 25, 1395-1397 (2013)

Zaoui, W.S., Kunze, A., Vogel, W., Berroth, M., Butschke, J., Letzkus, F., Burghartz, J.: Bridging the gap between optical fibers and silicon photonic integrated circuits. Opt. Express 22, 1277-1286 (2014)

Zhang, C., Sun, J.H., Xiao, X., Sun, W.M., Zhang, X.J., Chu, T., Yu, J.Z., Yu, Y.D.: High efficiency grating coupler for coupling between single-mode fiber and SOI waveguides. Chin. Phys. Lett. 30, 014207 (2013)

Zhong, Q., Veerasubramanian, V., Wang, Y., Shi, W., Patel, D., Ghosh, S., Samani, A., Chrostowski, L., Bojko, R., Plant, D.V.: Focusing-curved subwavelength grating couplers for ultra-broadband silicon photonics optical interfaces. Opt. Express 22, 18224-18231 (2014)

Publisher's Note Springer Nature remains neutral with regard to jurisdictional claims in published maps and institutional affiliations. 